\title{
Pengaruh Pelapisan Emulsi Minyak Wijen dan Minyak Sereh terhadap Mutu dan Masa Simpan Buah Jeruk Siam (Citrus nobilis Lour)
}

\section{The Influence of Coating Sesame and Citronella Oil Emulsion to the Quality and Storage Period of Siam Citrus Fruits (Citrus nobilis Lour)}

\author{
Andri Frans Kalvin Gurning, I Made Supartha Utama, Ni Luh Yulianti \\ Program Studi Teknik Pertanian, Fakultas Teknologi Pertanian Universitas Udayana. \\ Email: andrigurning91@yahoo.com
}

\begin{abstract}
Abstrak
Tujuan dari penelitian ini adalah untuk mengetahui pengaruh campuran konsentrasi yang berbeda antara minyak wijen dan minyak sereh dalam air sebagai bahan pelapis pada kualitas buah jeruk selama penyimpanan pada suhu kamar. Konsentrasi emulsi minyak wijen bervariasi $0 \%, 0.5 \%$, dan $1 \%$ dalam kombinasi minyak serah $0 \%, 0.5 \%, 1 \%$, dan $1.5 \%$. Bahan tambahan yang digunakan untuk membuat emulsi adalah $1 \%$ dari tween $80,0.5 \%$ asam oleat, dan alkohol 3\%. Buah kontrol tanpa perlakuan juga disiapkan untuk perbandingan. Percobaan dilakukan dengan menggunakan Rancangan Acak Lengkap (RAL) dengan tiga ulangan. Hasil penelitian menunjukkan bahwa perlakuan campuran minyak wijen dan minyak sereh signifikan mempengaruhi mutu dan masa simpan buah jeruk. Konsentrasi gabungan dari $0.5 \%$ minyak wijen dan $0.5 \%$ minyak sereh memberikan hasil terbaik yang mampu mengurangi susut bobot, kerusakan pembusukan, perubahan $\mathrm{pH}$ dan total padatan terlarut jus buah, dan kekerasan buah.
\end{abstract}

Kata kunci: jeruk, mutu, masa simpan, konsentrasi, pelapisan emulsi

\begin{abstract}
The purpose of this research is knowing the influence of different consentration mixture between sesame and citronella oil in water as coating material on the quality of citrus fruits during storage at room temperature. Consentration sesame oil emulsion varied $0 \%, 0.5 \%$, and $1 \%$ in citronella oil combination $0 \%, 0.5 \%, 1 \%$ and $1.5 \%$. The additional ingredients used to make emulsions were $1 \%$ of tween $80,0.5 \%$ oleic acid, and $3 \%$ alcohol. Untreatment control fruit was also prepared for comparison. The experiment was conducted using a Completely Randomized Design (CRD) with three replications. The results showed that the treatment of sesame and citronella oil significantly affected the quality and storage period of citrus fruits. The combined concentration of $0.5 \%$ sesame oil and $0.5 \%$ citronella oil provides the best results which can reduce weight loss, decay damage, $\mathrm{pH}$ alteration and total dissolved solids of fruit juice, and fruit hardness.
\end{abstract}

Keyword: citrus, quality, storage periode, consentration, emulsion coating

\section{PENDAHULUAN}

Jeruk siam merupakan anggota jeruk keprok dengan nama ilmiah Citrus nobilis lour. Dinamakan jeruk siam karena berasal dari Siam (Thailand). Di negara asalnya, jeruk ini dikenal dengan nama som kin wan. Sampai saat ini sebenarnya belum ada data resmi tentang kapan dan dimana tepatnya jeruk siam pertama kali didatangkan ke Indonesia. Tumbuhan ini merupakan tanaman yang dapat tumbuh baik di daerah tropis dan subtropics. Beberapa proses hidup yang penting pada buah jeruk adalah respirasi, transpirasi, dan proses pematangan buah. Proses (sifat) biokimia tersebut menurunkan mutu kesegaran buah jeruk yang dapat dilihat dari penampakan, susut bobot dan penurunan nilai gizinya (Handoko, 2000). Buah jeruk harus dipanen tepat saat tua/matang. Buah jeruk siam perlu penanganan pascapanen yang tepat.

Menurut Pangestuti (2007), buah jeruk kebanyakan disimpan dalam kondisi ruang apalagi dalam jumlah sangat besar, sehingga biasanya hanya dapat bertahan selama 2 minggu karena adanya resiko kebusukan sehingga perlakuan pelapisan buah jeruk sangat dianjurkan. Adanya respirasi menyebabkan buah menjadi masak dan tua yang ditandai dengan proses perubahan fisik, kimia, dan biologi antara lain proses 
pematangan, perubahan warna, pembentukan aroma dan kemanisan, pengurangan keasaman, pelunakan daging buah dan pengurangan bobot. Laju respirasi dapat digunakan sebagai petunjuk untuk mengetahui daya simpan sayur dan buah setelah panen. Semangkin tinggi laju respirasi, semakin pendek umur simpan. Bila proses respirasi berlanjut terus, buah akan mengalami kelayuan dan akhirnya terjadi pembusukan yang sehingga zat gizi hilang (Sutopo, 2011).

Salah satu cara untuk menjaga mutu dan masa simpan buah jeruk dengan baik adalah dengan melakukan pelapisan emulsi minyak wijen dan minyak sereh pada buah jeruk. Penggunaan pelapisan emulsi minyak wijen dan minyak sereh merupaka salah satu cara penanganan pasacapanen buah jeruk, dimana perlakuan pelapisan emulsi minyak wijen dan minyak sereh merupakan cara yang efektif untuk memperpanjang masa simpan dan mutu buah jeruk selama penyimpanan.

Penggunaan pelapisan emulsi minyak wijen mempunyai manfaat yaitu minyak wijen memiliki kesetimbangan yang tinggi dan ketahanan dari kerusakan dan oksidasi, serta mengandung zat tidak tersabunkan dalam jumlah relatif tinggi. Sedangkan penggunaan pelapisan minyak sereh juga bermanfaat untuk menghambat laju pertumbuhan mikroorganisme, minyak sereh wangi, daun selam dan oregano dapat menekan sejumlah bakteri seperti, $E$. coli, Salmonela dan Stapphylococcus pada tingkat kurang dari $2 \%$, bahkan minyak timus sangat efektif membunuh E.coli hanya pada konsentrasi $0,03 \%$. Hammer et al. (1999) menunjukkan bahwa minyak sereh mempunyai sifat antibakteri terhadap Acinetobacter baumanii, Aeromonas sobria, Enterococcus faecalis, Escherichia coli, Klebsiella pneumoniae, Pseudomonas aeruginosa, Salmonella typhimurium, Serratia marcescens dan Staphylococcus aureus. Berdasarkan hal tersebut, maka penelitian ini bertujuan untuk mengetahui pengaruh pelapisan emulsi minyak wijen dan minyak sereh terhadap mutu dan masa simpan buah jeruk siam (Citrus Nobilis Lour).

\section{METODE}

\section{Waktu dan Tempat}

Penelitian ini dilakukan di Laboratorium Pascapanen, Fakultas Teknologi Pertanian, Universitas Udayana pada bulan Januari sampai Februari 2014.

\section{Bahan dan Alat Penelitian}

Alat yang digunakan dalam penelitian ini antara lain chamber, gelas ukur, nampan, meja, pisau, timbangan digital (merk Adventurer ${ }^{T M}$ Pro Av 8101, Ohaus New
York, USA), blender merk Kris ${ }^{R}$, refractometer (merk labo 10807), texture analyzer (merk T.A XT plus, England) dan $\mathrm{pH}$ meter. Bahan yang digunakan dalam penelitian antara lain buah jeruk siam (citrus nobilis lour) yang diperoleh dari Desa Bunutin, Kintamani, Bangli dengan bentuk dan ukuran yang sama dengan kriteria warna hijau. Minyak sereh, minyak wijen, tween 80, asam oleat (oleic acid), alkohol (95\%), dan air.

\section{Rancangan Penelitian}

Rancangan penelitian yang digunakan dalam penelitian ini adalah Rancangan Acak Lengkap (RAL) dengan dua faktorial perlakuan. Pertama faktor perlakuan konsentrasi minyak wijen yang terdiri atas konsentrasi $0 \%$ (W0), $0,5 \%$ (W1), $1 \%$ (W2), kedua faktor perlakuan konsentrasi minyak sereh yang terdiri atas konsentrasi $0 \%$ (S0), 0,5\% (S1), 1\% (S2), 1,5\% (S3). Kombinasi konsentrasi campuran minyak wijen dengan minyak sereh dalam emulsi menjadi 12 kombinasi perlakuan, yaitu W0S0, WOS1, WOS2, W0S3, W1S0, W1S1, W1S2, W1S3, W2S0, W2S1, W2S2 dan W2S3.

Perlakuan diulang sebanyak tiga kali dengan penyimpanan pada suhu ruang $\left(27-30^{\circ} \mathrm{C}\right)$. Data yang diperoleh dianalisis dengan analisis sidik ragam dan apabila pengaruh perlakuan signifikan, maka dilanjutkan dengan uji Beda Nyata Terkecil (BNT) terhadap rata-rata perlakuan. Terdapat 36 satuan percobaan dan setiap percobaan terdiri dari 36 buah untuk tujuh kali pengamatan. Terdiri dari 15 buah digunakan untuk pengamatan susut bobot, intensitas kerusakan dan warna serta 21 buah akan digunakan untuk pengamatan pengukuran kekerasan, total padatan terlarut dan $\mathrm{pH}$ (tiga buah/hari).

\section{Prosedur Penelitian \\ Proses Pembuatan Emulsi}

Pembuatan emulsi dilakukan pada tiap-tiap konsentrasi campuran minyak wijen dan minyak sereh sebagai pelapis yang akan digunakan dalam penelitian. Emulsi yang dibuat terdiri dari campuran minyak sereh $(0 \%$, $0.5 \%, 1 \%, 1.5 \%)$, minyak wijen $(0 \%, 0.5 \%, 1 \%)$, tween $80(1 \%)$, asam oleat $(0.5 \%)$, alkohol (3\%) dan air dalam $1000 \mathrm{ml}$ emulsi volume/volume. Pencampuran bahanbahan penyusun emulsi dilakukan menggunakan blender selama lima menit. Tidak adanya gumpalangumpalan pada emulsi yang telah diblender menandakan emulsi stabil (homogeny). 


\section{Tahap Sortasi Buah}

Proses sortasi dilakukan untuk membedakan dan memilah agar buah yang digunakan dalam penelitian seragam dan tidak adanya kerusakan sebelum perlakuan. Kriteria buah jeruk segar yang digunakan dalam penelitian ini ditandai dengan warna hijau kekuning-kuningan dan tidak adanya kerusakan atau cacat pada permukaan buah. Ukuran buah jeruk yang digunakan antara lain diameter berkisar 4-5 cm dan panjang buah jeruk berkisar 3-4 cm. Panjang buah jeruk diukur mulai dari pangkal hingga ujung buah.

\section{Tahap Pelapisan Emulsi}

Metode yang digunakan dalam pemberian lapisan emulsi dilakukan dengan metode pengolesan emulsi yang telah dibuat kemudian buah jeruk dimasukkan dalam chamber dan lapisan emulsi dioleskan pada masing-masing buah jeruk menggunakan kuas agar proses pengolesan emulsi merata pada masing-masing buah jeruk. Kemudian sampel buah jeruk yang sudah dioleskan emulsi ditiriskan atau diangin-anginkan beberapa menit hingga kering.

\section{Tahap Peletakan}

Buah jeruk yang sudah diberi perlakuan pelapisan emulsi disusun pada nampan yang diletakkan di atas meja sesuai dengan kelompok perlakuan yang disimpan pada suhu kamar.

\section{Tahap Pengamatan}

Pada penelitian ini pengamatan dilakukan dengan cara subjektif dan objektif dimana pengamatan dimulai setelah setiap buah segar telah mengalami pelapisan menggunakan emulsi. Pengamatan secara subjektif dilakukan terhadap warna, kesegaran buah, kekerasan buah dan intensitas kebusukan yang dijelaskan secara deskriptif yang dilakukan setiap hari oleh peneliti.

Pengamatan secara objektif dilakukan terhadap perubahan berat dengan cara ditimbang menggunakan timbangan analitik, warna menggunakan colorimeter, kekerasan menggunakan tekstur analyzer, total padatan terlarut menggunakan refraktometer, keasaman menggunakan digital $\mathrm{Ph}$-meter dan pengukuran intensitas kebusukan menggunakan rating kemudian dimasukan kedalam rumus intensitas pembusukan pada tiap unit percobaan. Pengamatan objektif dilakukan setiap 3 hari sekali dengan masing-masing parameter yang diamati. Berikut adalah gambaran diagram alir penelitian pelapisan buah jeruk siam dengan campuran minyak nabati dan minyak sereh.

\section{Parameter yang diamati \\ Kekerasan Buah Jeruk}

Pengukuran kekerasan buah jeruk dilakukan dengan menggunakan alat texture analyzer (TA.XTplus, England). Alat texture analyzer dihubungkan pada komputer, pengaturan kecepatan tusukan dan dalam tusukan dapat diatur pada software "Texture Exponent 32". Kecepatan tusukan yang digunakan dalam pengukuran kekerasan buah jeruk $5 \mathrm{~mm} / \mathrm{s}$ dengan kedalamam $10 \mathrm{~mm}$. Penekanan yang dilakukan sampai menembus daging jeruk yang telah disesuaikan dengan ketebalan daging jeruk dan kemudian jeruk ditekan dengan jarak tertentu. Jarum pengukuran harus dipastikan menempel pada permukaan sampel lalu klik "quik run a test" pada komputer kemudian secara otomatis jarum akan mengukur tingkat kekerasan daging jeruk.

Uji kekerasan buah jeruk diukur berdasarkan tingkat ketahanan buah terhadap tusukan yang dilakukan. Hasil dari uji kekerasan akan muncul dalam bentuk grafik pada layar komputer dengan nilai kekerasan dalam satuan $\mathrm{kg} / \mathrm{cm}^{2}$. Pengukuran dilakukan pada 2 titik bagian buah, dengan mengunakan 2 buah dengan rentan waktu 3 hari sekali. Data yang diperoleh merupakan hasil rata-rata dari kedua data pengukuran tersebut. Kemudian perubahan yang di peroleh di tuangkan dalam bentuk grafik.

\section{Intensitas Kerusakan}

Pada proses pengamatan presentase pembusukan merupakan parameter yang diamati secara visual dan dilakukan satu persatu pada masing-masing sampel buah jeruk. Pengamatan ini dilakukan oleh peneliti dengan menggunakan rumus yang sudah tersedia untuk mengukur presentase pembusukan pada masingmasing buah jeruk (Kremer and Untertenshofer, 1967). Tingkat Kerusakan diukur dengan persentase 0-25\% dan apabila tingkat kerusakan pada buah jeruk $>25 \%$ maka buah jeruk dianggap sudah rusak dan harus dikeluarkan dari sampel atau dibuang. Kriteria yang dikatakan terjadinya kerusakan seperti: adanya bercakbercak pada permukaan buah jeruk, keriput pada kulit luar jeruk, kekerasan jeruk yang lembek, dan mengeluarkan aroma busuk.

\section{Susut Bobot}

Pengukuran susut bobot dilakukan dengan cara penimbangan menggunakan timbangan analitik. Pengukuran perubahan berat dihitung dalam persen berat awal buah salak hari ke 0 (Wo) dibandingkan perubahan berat setelah proses penyimpanan (Wt). Hasil penimbangan dinyatakan dalam persen bobot yang dihitung dengan rumus: 


$$
\text { Susut bobot }(\%)=\frac{W o-W t}{W o} \times 100
$$

Keterangan: $\quad$ Wo $=$ Bobot buah awal

$\mathrm{Wt}=$ Bobot buah hari ke-t

Pengukuran dilakukan tiap 3 hari sekali dan tiap sampel diukur 2 buah yang sama. Data yang diperoleh merupakan hasil rata-rata dari kedua data pengukuran tersebut. Kemudian perubahan yang di peroleh di tuangkan dalam bentuk grafik.

\section{Total Padatan Terlarut}

Dalam menguji total padatan terlarut pada buah jeruk alat yang digunakan untuk mengukur adalah refraktometer dalam satuan ${ }^{\circ}$ Brix. Sampel yang akan diukur kadar total padatan terlarutnya terlebih dahulu dihancurkan atau dihaluskan pada kaca sensor yang terdapat pada refraktometer, lalu hidupkan alat dan dikalibrasi. Kalibrasi dilakukan dengan meneteskan beberapa tetes cairan aquades pada lensa tempat untuk meletakkan sampel. Setelah dikalibrasi, bersihkan kembali lensa lalu ambil sedikit sampel dan letakkan pada lensa yang terdapat pada alat maka akan muncul angka pada layar. Angka inilah yang menunjukkan kadar total padatan terlarut pada sampel. Pengukuran kadar total padatan terlarut dilakukan setiap 3 hari sekali dan tiap sampel diukur 2 buah. Data yang diperoleh merupakan hasil rata-rata dari kedua data pengukuran tersebut. Kemudian perubahan yang diperoleh dituangkan dalam bentuk grafik.

\section{Keasaman (pH) jus buah}

Pengukuran total asam pada buah jeruk menggunakan pH meter digital dengan cara mencelupkan ujung alat pada sampel yang telah dihaluskan kemudian tunggu hingga angka pada alat berhenti berubah. Angka yang terdapat pada $\mathrm{pH}$ meter ini menunjukan derajat keasaman sampel. Setelah melakukan pengukuran pertama celupkan $\mathrm{pH}$ meter pada cairan aquades hingga menunjukan $\mathrm{pH}$ normal 7 sebelum digunakan pada pengukuran sampel yang lainnya. Pengukuran dilakukan setiap 3 hari sekali dan tiap sampel diukur 2 buah. Data yang diperoleh merupakan hasil rata-rata dari kedua data pengukuran tersebut. Kemudian perubahan yang diperoleh di tuangkan dalam bentuk grafik.

\section{Pengamatan Deskriptif}

Pengamatan deskriptif merupakan pengamatan yang dilakukan setiap hari untuk mendeskripsikan perubahan warna, kekerasan ataupun kerusakan yang terjadi pada setiap sampel selama penelitian berlangsung. Pendeskripsian dilakukan berdasarkan pengamatan peneliti, hal ini bertujuan agar pada setiap harinya kriteria pengamatan yang diamati sama.

\section{HASIL DAN PEMBAHASAN}

\section{Pengamatan Objektif}

\section{Susut Bobot pada Buah Jeruk}

Susut bobot merupakan salah satu faktor yang mengindikasikan mutu buah jeruk. Perubahan terjadi bersamaan dengan lamanya waktu simpan dimana semakin lama jeruk disimpan maka bobot jeruk semakin berkurang. Menurut Pantastico (1986), meningkatnya susut bobot sebagian besar disebabkan transpirasi yang tinggi. Buah jeruk tanpa perlakuan mengalami peningkatan susut bobot terbesar pada suhu penyimpanan ruang.

Hasil analisis sidik ragam menunjukkan bahwa interaksi kedua faktor berpengaruh sangat nyata $(\mathrm{P}<0.05)$ pada penyimpanan hari ke 3, 9, 12, 15, dan 18. Hasil analisis statistika keragaman terhadap susut bobot buah jeruk dapat dilihat pada Gambar 1,2 dan 3 .

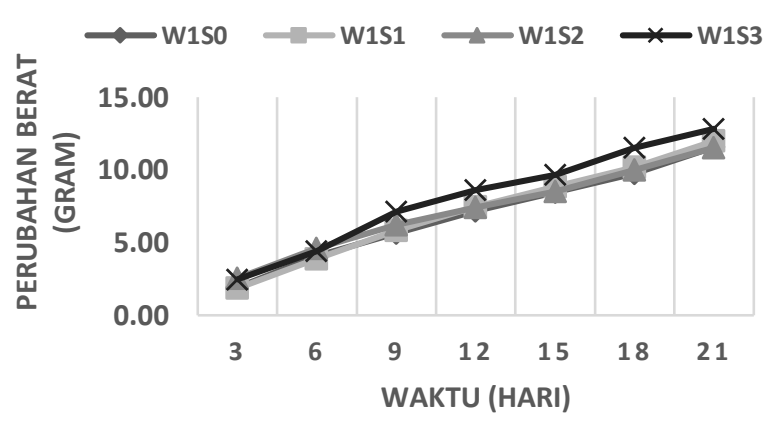

Gambar 1. Grafik Susut Bobot Buah Jeruk pada perlakuan S0, S1, S2 dan S3 tanpa pencampuran minyak wijen (W0).

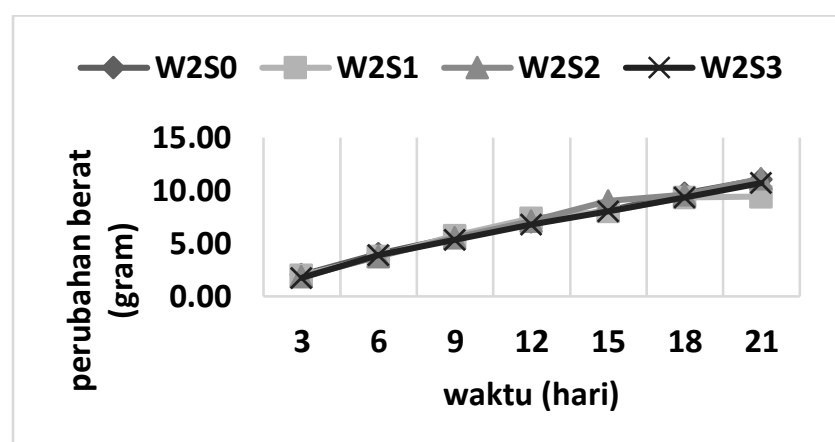

Gambar 2. Grafik Susut Bobot Buah Jeruk pada perlakuan S0, S1, S2 dan S3 dengan pencampuran minyak wijen $0.5 \%(\mathrm{~W} 1)$. 


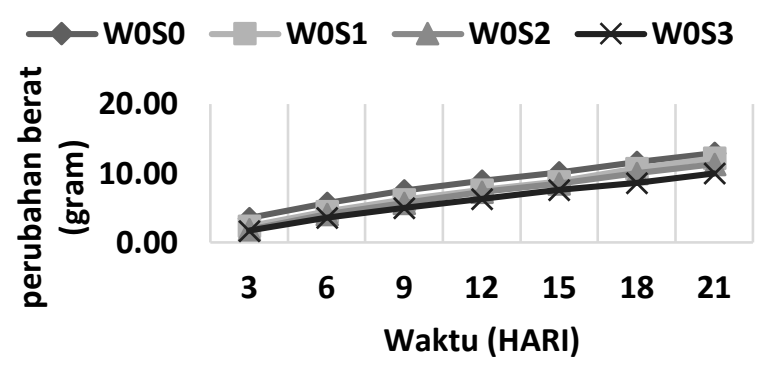

Gambar 3. Grafik Susut Bobot Buah Jeruk pada perlakuan S0, S1, S2 dan S3 dengan pencampuran minyak wijen $1 \%$ (W2)

Secara umum, berdasarkan Data yang diperoleh Gambar 1,2 dan 3 dapat dilihat bahwa perubahan susut bobot pada buah jeruk semakin lama semakin besar seiring lama waktu penyimpanan pada seluruh perlakuan. Hal ini dikarenakan semakin lama penyimpanan maka laju respirasi dan transpirasi juga akan meningkat yang memacu terjadinya laju kehilangan air yang semakin besar pula.

Perlakuan kontrol yaitu buah yang tidak diberikan pelapis memiliki nilai susut bobot tertinggi. Perlakuan kontrol kerusakan buah mulai terjadi lebih awal dibandingkan perlakuan lainnya, hal ini ditunjukkan oleh kondisi buah jeruk perlakuan kontrol yang mengalami kerusakan berupa pembusukan dan pengeriputan yang lebih awal dibandingkan perlakuan lainnya. Laju kehilangan air disebabkan karena lepasnya karbon pada saat proses respirasi sehingga susut bobot pada buah semakin besar (Thompson, 2002).

Kehilangan air selama penyimpanan tidak hanya menurunkan berat, tetapi juga menurunkan mutu dan menimbulkan kerusakan. Buah dengan susut bobot tinggi akan menyebabkan buah kehilangan kesegarannya, buah menjadi kisut dengan kulit berkerut sehingga penampilan buah menjadi tidak menarik dan tidak lagi layak dipasarkan.

Sama halnya dengan parameter kekerasan dan intensitas kerusakan, interaksi perlakuan minyak wijen $0 \%$ dan minyak sereh 1,5\% (W0S3) juga memberikan respon yang positif pada parameter susut bobot, dimana pada perlakuan tersebut, perubahan nilai susut bobot yang dihasilkan dari waktu kewaktu cenderung lebih kecil dibandingkan perlakuan lainnya.

\section{Perubahan Kekerasan Buah Jeruk}

Tingkat kekerasan buah jeruk pada umumnya akan menurun selama penyimpanan. Semakin lunak kulit buah maka dapat dikatakan buah telah rusak dan tidak disukai oleh konsumen. Penurunan kekerasan ini juga disebabkan oleh adanya respirasi dan transpirasi. Pada proses respirasi akan mengakibatkan pecahnya karbohidrat menjadi senyawa-senyawa yang lebih sederhana, dengan adanya pemecahan karbohidrat ini maka akan menyebabkan pecahnya jaringan pada buah sehingga buah menjadi lunak. Proses respirasi ini menyebabkan kelanjutan pematangan pada buah. Sedangkan pada proses transpirasi akan terjadi penguapan air yang menyebabkan buah menjadi layu dan mengerut sehingga buah menjadi lunak. Hal ini terjadi karena sebagian air pada buah mengalami pengguapan sehingga ketegaran buah menjadi menurun.

Hasil analisis sidik ragam menunjukkan bahwa interaksi antara perlakuan minyak wijen dan minyak sreh berpengaruh sangat nyata $(\mathrm{P}<0.05)$ pada penyimpanan hari ke 3, 9, 12, 15 dan 18 . Hasil analisis statistika keragaman terhadap kekerasan buah jeruk dapat dilihat pada Gambar 4,5 dan 6.

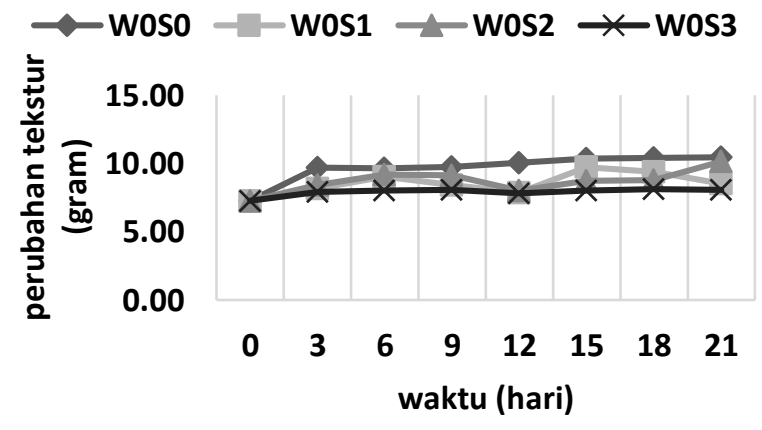

Gambar 4. Grafik Kekerasan Buah Jeruk pada perlakuan S0, S1, S2 dan S3 tanpa pencampuran minyak wijen (W0).

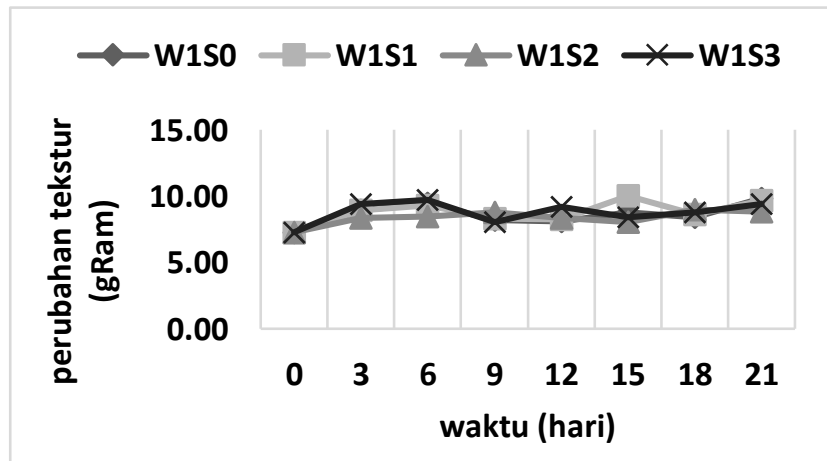

Gambar 5. Grafik Kekerasan Buah Jeruk pada perlakuan S0, S1, S2 dan S3 dengan pencampuran minyak wijen $0.5 \%$ (W1). 


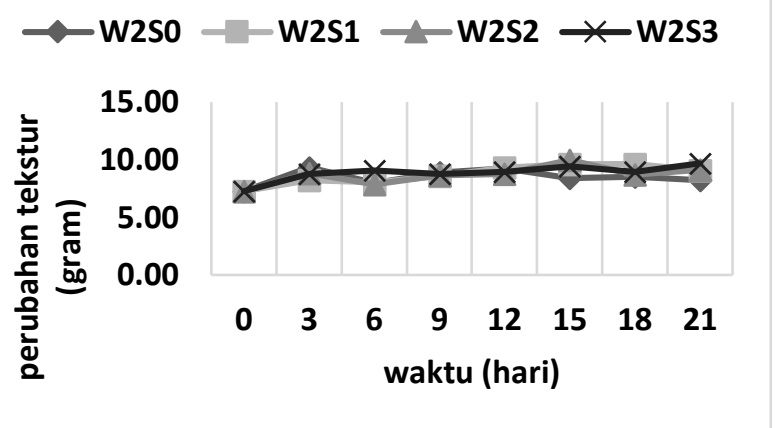

Gambar 6. Grafik Kekerasan Buah Jeruk pada perlakuan S0, S1, S2 dan S3 dengan pencampuran minyak wijen $1 \%(\mathrm{~W} 2)$.

Selanjutnya Gambar 4, 5 dan 6 dapat dilihat bahwa perubahan kekerasan pada kontrol lebih besar apabila dibandingkan dengan kekerasan buah yang diberikan pelapisan.

Berdasarkan beberapa hal tersebut diatas, menunjukan bahwa buah yang dilapisi dengan emulsi campuran minyak wijen konsentrasi $0 \%$ dengan minyak sereh $1,5 \%$ (W0S3) mengalami proses pematangan yang lebih lambat dibandingkan perlakuan lainnya. Selain itu, rendahnya nilai perubahan kekerasan pada perlakuan minyak wijen konsentrasi $0 \%$ dengan minyak sereh $1,5 \%$ (WOS3) dikarenakan sifat penghalang yang berasal minyak sereh dapat menghambat perkembangan mikroba pembusuk. (Burt, 2004) menyatakan bahwa kandungan minyak atsiri pada daun sereh dapat mengganggu pertumbuhan mikroba dengan cara mengurangi laju respirasi sehingga oksigen yang diperlukan untuk perkembangan mikroba akan terhalang. Selain itu, rendahnya nilai kekerasan pada perlakuan tersebut juga dikarenakan penggunaan pelapisan minyak sereh sebagai bahan pelapis dapat menghambat oksigen yang masuk kejaringan lebih besar sehingga enzim-enzim yang menyebabkan penurunan nilai kekerasan menjadi kurang aktif.

\section{Perubahan Intensitas Kerusakan Jeruk}

Perubahan fisiologis yang tidak terkontrol dengan baik akan mempercepat proses penurunan mutu yang akan berakhir dengan kebusukan (Aked, 2000). Hasil analisis sidik ragam menunjukkan bahwa interaksi kedua faktor berpengaruh sangat nyata $(\mathrm{P}<0.05)$ terhadap intensitas kerusakan buah jeruk pada penyimpanan hari ke $6,9,12,15$, dan 18 . Hasil analisis statisika keragaman terhadap kebusukan buah jeruk dapat dilihat pada Gambar 7, 8, dan 9.

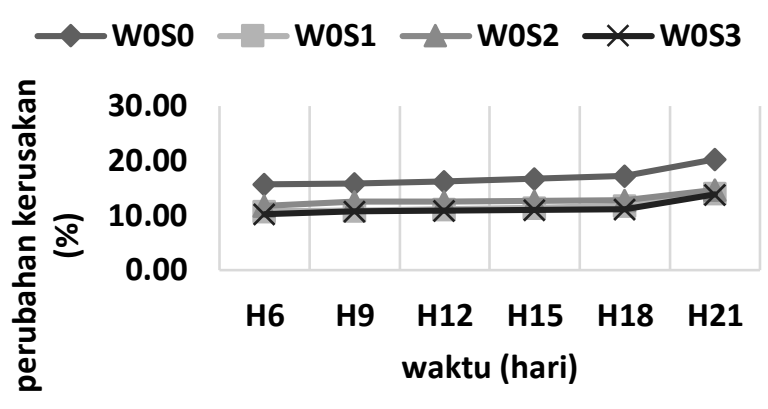

Gambar 7. Grafik kerusakan Buah Jeruk pada perlakuan S0, S1, S2, dan S3 tanpa pencampuran dengan minyak wijen (W0).

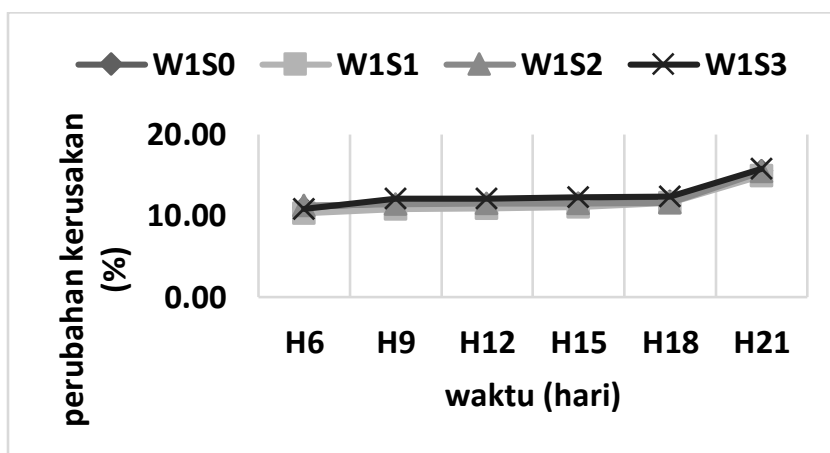

Gambar 8. Grafik kerusakan Buah Jeruk pada perlakuan S0, S1, S2, dan S3 dengan pencampuran dengan minyak wijen $0.5 \%$ (W1).

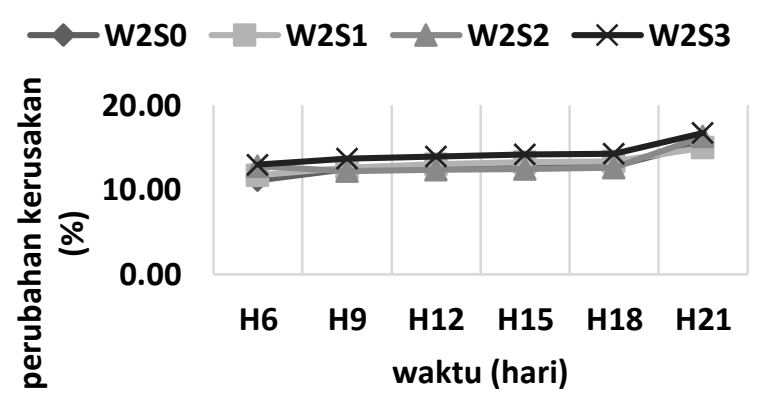

Gambar 9. Grafik kerusakan Buah Jeruk pada perlakuan S0, S1, S2, dan S3 dengan pencampuran dengan minyak wijen $1 \%$ (W2).

Berdasarkan Gambar 7, 8 dan 9 diatas perubahan intensitas kerusakan pada buah jeruk semakin hari menunjukan peningkatan semakin besar. Parameter susut bobot menunjukan hasil yang sama pada perubahan intensitas kerusakan yang terbesar juga terjadi pada perlakuan kontrol hingga mencapai 15,47 $\%$ pada hari ke 21 . Hal ini dikarenakan proses respirasi 
yang terjadi pada perlakuan kontrol lebih cepat dibandingkan perlakuan lainnya dan kondisi ini menyebabkan kebusukan buah yang terjadi pun menjadi semakin besar. Rendahnya intensitas kerusakan buah jeruk pada perlakuan minyak wijen $0 \%$ dan minyak sereh $1,5 \%$ (W0S3) pada setiap waktu pengamatan menunjukkan bahwa perlakuan minyak wijen $0 \%$ dan minyak sereh $1,5 \%$ (WOS3) mampu memberikan pelindungan terhadap buah jeruk dimana minyak sereh mampu menjadi bahan pelapis yang bersifat antimikroba berpotensi dapat mencegah kontaminan pantogen. Kombinasi antimikroba dalam pelapisan dapat mengendalikan pertumbuhan mikroba pada buah dan sayuran serta memperpanjang masa simpan dan mempertahankan mutu (Quintayalla dan Vicini 2002).

\section{Pengamatan Deskriptif}

Pengamatan deskriptif merupakan pengamatan yang dilakukan setiap hari untuk mendeskripsikan perubahan warna, kekerasandan kerusakan yang terjadi pada setiap sampel selama penelitian berlangsung. Proses pendeskripsian dilakukan berdasarkan pengamatan peneliti, hal ini bertujuan agar pada setiap harinya kriteria pengamatan yang diamati memiliki standar yang sama.

\section{Warna Buah Jeruk}

Menurut Makfoeld (1992) Pengamatan deskriptif yang dilakukan pada buah jeruk salah satunya merupakan parameter warna buah. Berdasarkan pengamatan yang dilakukan pada hari ke-0 dan ke-1 masing-masing perlakuan belum menunjukan perubahan warna yang terlihat. Berdasarkan pengamatan yang dilakukan pada hari ke-0, 1 dan hari ke-2 masing-masing perlakuan belum menunjukan perubahan warna yang terlihat. Perubahan warna baru dapat dilihat pada hari ke-3 berupa perubahan warna menuju stadia hijau muda, yang ditunjukkan oleh perlakuanW0S0, W1S2, W1S3, dan W2S3 dengan masing-masing satu buah pada tiap ulangannya. Perubahan warna pada stadia hijau kuning terjadi pada hari ke-6 pada beberapa perlakuan.

Perlakuan W0S0 dan W2S3 terdapat rata-rata 2 buah pada tiap ulangannya yang berubah menuju pada stadia hijau jingga, sedangkan pada W0S3, W1S0, W1S2,W1S3 dan W2S2 ada satu buah pada setiap perlakuannya. Pengamatan hari ke-5 hampir $90 \%$ buah pada tiap-tiap perlakuan telah mencapai stadia hijau kuning. Perlakuan W0S0 dan W2S3 pada hari ke-6 merupakan perlakuan yang paling pertama mengalami perubahan warna stadia kuning pada beberapa buah. Perlakuan yang lainnya masih memasuki stadia hijau jingga ataupun hijau kuning. Pengamatan hari ke-9 semua perlakuan telah melewati stadia warna hijau jingga. Seluruh perlakuan telah memasuki stadia kematangan warna kuning pada hari ke-12. Perlakuan WOS0 terjadi pengeriputan kulit buah pada rata-rata 2 buah pada setiap perlakuan pada hari ke 17 . Kehilangan air yang cukup besar pada perlakuan kontrol (W0S0) menyebabkan buah menjadi keriput. Pengamatan hari ke 21 telah banyak buah tomat yang mengalami pengeriputan pada kulit pada perlakuan kontrol hampir $40 \%$ dari 45 buah yaitu sejumlah 18 buah. Perlakuan W0S2, W2S2 dan W2S3 masing-masing terdapat minimal satu buah yang mengalami pengeriputan pada tiap ulangannya.

\section{Kekerasan Buah Jeruk}

Kekerasan buah Jeruk yang diamati pada hari ke-1 sampai ke-5 seluruh perlakuan tidak menunjukan adanya perubahan dimana kekerasan buah jeruk yang diamati masih dalam kondisi keras. Perubahan kekerasan buah jeruk mulai dapat dirasakan oleh panelis pada saat buah memasuki stadia warna kuning yaitu hari ke-14 yang terjadi pada perlakuan W0S0 dan W2S3. Pengamatan hari ke 18 hampir setiap perlakuan telah mengalami perubahan kekerasan dibandingkan hari pertama. Seiring lamanya waktu penyimpanan kekerasan buah jeruk yang dirasakan penelis semakin menurun.

\section{Kerusakan Buah Jeruk}

Kerusakan pada buah jeruk hari ke-1 dan ke-2 tidak menunjukan adanya perubahan intensitas kerusakan yang signifikan. Pengamatan hari ketiga terdapat beberapa kerusakan yang terjadi pada perlakuan pada buah yang digunakan untuk pengamatan destruktif diantaranya pada perlakuan kontrol, W1S2, W1S3, W2S1, W2S3, W0S2, W2S0 dan W2S2. Kerusakan yang terjadi adalah kebusukan pada pangkal buah. Pengamatan hari ke-12 buah yang mengalami kebusukan harus dipisahkan dari perlakuan karena sudah mencapai lebih dari $25 \%$ hal ini dilakukan untuk mencegah kebusukan pada buah yang lainya.

Pengamatan hari ke- 15 terjadi pengantian buah pada perlakuan WOS1U2 sebanyak satu buah, hal ini dikarenakan terjadinya kebusukan pada perlakuan tersebut. Pengantian buah dilakukan guna penyeragaman sampel sebelum dilakukan pengamatan intensitas kerusakan hari ke-16. Pengamatan intensitas kerusakan dilakukan pada hari ke-16. Pengamatan hari ke-16 kerusakan pada perlakuan W0S3U1, W2S2U1 dan U3, serta W2S3U2 dan U3 yang telah mencapai rating 4 (12-15\%) masing-masing satu buah pada W2S3 terdapat satu buah yang telah mencapai rating 5 . 
Perlakuan yang lainnya masih mengalami kerusakan dibawah rating 4. Pengamatan hari berikutnya terjadi kebusukan seiring dengan lama waktu penyimpanan dengan perlakuan W0S0, W2S2 dan W2S3 lebih mendominasi jika dibandingkan kerusakan pada perlakuan lainnya.

\section{KESIMPULAN DAN SARAN}

\section{Kesimpulan}

Hasil pembahasan mengenai beberapa parameter pengamatan dapat diambil kesimpulan bahwa perlakuan pelapisan dengan emulsi minyak wijen dengan minyak sereh sebagai pelapis pada buah jeruk memberikan pengaruh signifikan terhadap perubahan mutu dan memperpanjang masa simpan buah jeruk. Perlakuan pelapisan dengan perbandingan minyak wijen konsentrasi $0 \%$ dengan minyak sereh 1,5\% merupakan perlakuan terbaik dalam mempertahankan mutu dan masa simpan dibandingkan perlakuan yang lainnya selama penyimpanan 21 hari pada suhu kamar.

\section{Saran}

Pemberian pelapisan dengan emulsi minyak wijen dan minyak sereh mampu menunjukan pengaruh yang nyata terhadap masa simpan dan mutu buah jeruk khususnya dengan konsentrasi minyak wijen $0 \%$ dan minyak sereh $1,5 \%$ menjadi perlakuan terbaik maka perlu dilakukan penelitian lebih lanjut mengetahui bagaimana pengaruh emulsi campuran minyak wijen dan minyak sereh dengan konsentrasi tersebut pada buah yang memiliki satu family dengan buah jeruk. Selain itu perlu dilakukan penyeragaman sampel buah masing-masing perlakuan untuk hasil pengujian yang lebih baik.

\section{DAFTAR PUSTAKA}

\section{- _. www.litbang.deptan.go.id. Minyak Wijen: "Raja Minyak Nabati" [internet]. Malang: Balai Penelitian Tanaman Tembakau dan Serat (Balittas); 1997-2011. \\ Aked, J. 2000. Fruits and Vegetables in Stability and shelf-life of food, in Kilcast. $\mathrm{K}$ and Subramaniam, P (Eds.): The Stability and Shelf- life of Food, CRC Press.}

Anonim. 1999. Peluang Usaha dan Pembudidayaan Jeruk Siam. Penebar Swadaya. Jakarta

Apandi. 1984. Teknologi Buah dan Sayuran. Alumni, Bandung.
Burt, S. 2004. Essential oils: their antibacterial properties and potential applications in foods: a review. Intl. J. Food Microbiol.94: 223-253.

Departemen Pertanian. 1994. Penuntun Budiddaya Buah-buahan (Jeruk). Direktorat

Guenther, Ernest. 1948. The Essential Oil Vol. 4 (Minyak Atsiri, terjemahan Ketaren, pokok bahasan: Sereh Dapur). Universitas Indonesia Press. Jakarta.

Hammer, K.A., C.F. Carson dan T.V. Riley. 1999. Antimicrobial activity of essemtial oils and other plants extract. J. Appl. Microbiol. 86:985-990.

Handoko, D. D., B. Napitupulu dan H. Sembiring., 2000. Penanganan Pasca Panen Buah Jeruk. Balai Pengkajian Teknologi Pertanian Sumatera Utara, Medan.Jakarta. Jenderal Pertanian Tanaman Pangan. 269 h.

Kadarisman, D., Sunarmani, dan M. Arintawati. 2004. Mempelajari Perubahan Fisika Dan Kimia Sari Buah Jeruk Siam (C. Nobilis Var Microcarpa) dan Proses.

Ma'mun dan Nurdjannah, N. 1993. Pengaruh Perajangan dan Lama Pelayuan terhadap Rendemen dan Mutu Minyak Serai Dapur (Cymbopogon citratus Stapf). Balai Penelitian Tanaman Rempah dan Obat. Bul. Litro. Vol VIII. No. 1. Hal: $42-45$. http://isjd.pdii.lipi.go.id/admin/jurnal/81934245 .pdf diakses tanggal 17 Agustus 2013.

Maizura, M., A. Fazilah, M.H. Norziah, and A.A. Karim. 2007. Antibacterial activity and mechanical properties of partially hydrolyzed sago starch-alginate edible film containing lemongrass oil. J. Food Sci. 72: 6: c324-c330.

Makfoeld D. 1993. Mikotoksin Pangan. Yogyakarta: Kanisius.

Makfoeld, D. 1992. Buah Klimakterik. Fakultas Pascasarjana Universitas Gadjah Mada. Yogyakarta

Muchtadi, T. R. 1992. Fisiologi Pascapanen Sayuran dan Buah-buahan. Departemen Pendidikan dan Kebudayaan. Jendral Pendidikan Tinggi. PAU. IPB. Bogor. 
Pangestuti, R., A. Supriyanto dan Suhariyono. 2007. Umur Simpan dan Perubahan Kualitas Jeruk Keprok SoE (Citrus reticulate Blanco) pada Umur Petik dan suhu Penyimpanan yang Berbeda. Balai Penelitian tananman Jeruk dan Buah Subtropika, Tlekung.

Pantastico, E. R. B, 1993. Fisiologi Pasca Panen. UGM-Press, Yogyakarta.

Pracaya, 2000. Jeruk Manis, Varietas, Budidaya dan Pascapanen. Penebar Swadaya, Jakarta.

Quintavalla, S. and L. Vicini. 2002. Antimicrobial food packaging in meat industry. Meat Sci. 62: 373380.

Saputera, Sutrisno., S. Susanti dan I. W. Budiastra, 2000. Pengkajian Penyimpanan Jeruk Besar (Citrus grandis L) Pengolahan Minimal dengan Kemasan Atmosfer Termodifikasi. Buletin Keteknikan Pertanian.

Satuhu, S. 1994. Penanganan dan Pengolahan Buahbuahan. Penebar Swadaya.

Setiawan, Ade Iwan, dan Yani trisnawati. 2003. Peluang Usaha dan Pembudidayaan Jeruk Siam. Penebar Swadaya. Jakarta

Siagian, H.F. Penggunaan Bahan Penjerat Etilen Pada Penyimpanan Pisang Barangan dengan Kemasan Atmosfer Termodifikasi Aktif. Fakultas Pertanian Universitas Sumatera Utara.

Sihombing, D.T.H., 1997. Ilmu Ternak Lebah Madu. Gadjah Mada University Press, Yogyakarta.

Siswadi. 2007. Penanganan Pasca Panen Buahbuahan dan Sayuran. Jurnal lnovasi Pertanian Vol. 6.

Suhardi. 1992. Penanganan Pascapanen Buah dan Sayuran. PAU Pangan dan Gizi.Yogyakarta.
Sutopo, 2011. Penanganan Panen dan Pasca Panen Buah Jeruk. http://www.kpricitrus.wordpress.com (30 Mei 2013).

Tambun, R. 2006. Buku Ajar Teknologi Oleokimia. Departemen Teknik Kimia Fakultas Teknik Universitas Sumatera Utara Medan.

Thomson, J.F, Mitchell, F.G, Rumsey, Kasmire, R.F, and Crisosto, C.H., 2002. Commercial Cooling Fruit, Vegetables, and Flower. University of California. Devision of Agricultural and Natural Recources Publication 21567.

Tranggono, 1992. Memperpanjang Umur Simpan Buah Salak Pondoh Dengan Penyimpanan Dalam Atmosfer Terkendali. Laporan Penelitian, PAU UGM, Yogyakarta.

Utama, I M. S. 2001. Penanganan Pascapanen Buah Dan Sayuran Segar. Universitas Udayana, Denpasar, Bali.

Utama, I M.S. 2008. Manual praktik laboratorium teknik pascapanen hortikultura. Program studi keteknikan pertanian. Fakultas teknologi pertanian. Universitas udayana.

Willes, J. V. (2000). Water Vapor Transmission Rates of Chitosan Film. Journal of Food Science. vol 60 , no 7.

Winarno, F. Moehammad Adnan. 1979. Fisiologi Lepas Panen. PT. Sastra Hudaya. Jakarta Pusat.

Winarno, F.G. 2002. Fisiologi lepas panen produk hortikultura. M-Brio Press, Bogor.

www.wikipedia.com. Minyak Nabati. 6 Juni 2013. 20.18 Wita. 